\title{
Short-chain fatty acid butyrate: A novel shield against chronic gastric ulcer
}

\author{
YAN ZHOU $^{1^{*}}$, XIAWEI $\mathrm{JI}^{2 *}$, JIAJING $\mathrm{CHEN}^{2}$, YAOYANG FU ${ }^{2}$, JUEWEI HUANG ${ }^{2}$, RUI GUO ${ }^{2}$, JINHUI ZHOU $^{2}$, \\ JIANKE CEN ${ }^{2}$, QIHAO ZHANG ${ }^{2}$, ANNE CHU $^{2}$, YINGPENG HUANG ${ }^{3}, \mathrm{CHANGLONG} \mathrm{XU}^{4}$ and FANGYAN WANG ${ }^{2}$ \\ ${ }^{1}$ Wenzhou Key Laboratory of Sanitary Microbiology, Key Laboratory of Laboratory Medicine, Ministry of Education, China, \\ School of Laboratory Medicine and Life Sciences, Wenzhou Medical University; ${ }^{2}$ Department of Pathophysiology, \\ School of Basic Medical Science, Wenzhou Medical University; Departments of \\ ${ }^{3}$ General Surgery and ${ }^{4}$ Gastroenterology, The Second Affiliated Hospital and Yuying Children's Hospital of \\ Wenzhou Medical University, Wenzhou, Zhejiang 325000, P.R. China
}

Received May 23,2020; Accepted December 14, 2020

DOI: $10.3892 /$ etm.2021.9760

\begin{abstract}
Butyrate is one of the most abundant short-chain fatty acids produced by intestinal bacteria. In the present study, the action of butyrate on chronic gastric mucosa lesions was investigated, as well as its underlying mechanism in mice. Male mice from the Institute of Cancer Research were randomly divided into three groups: Sham, model and butyrate groups. Butyrate was administered intragastrically for 7 days to butyrate group mice following the establishment of a gastric ulcer model. Hematoxylin and eosin staining, immunohistochemical analysis, enzyme-linked immunosorbent assay and quantitative polymerase chain reaction were used to determine the therapeutic effects and molecular mechanism of butyrate treatment. The findings demonstrated that butyrate induced a marked shift in superoxide dismutase and catalase activities, along with a decrease in malondialdehyde levels, thereby attenuating oxidative stress. Furthermore, butyrate decreased the levels of pro-inflammatory cytokines interleukin-1 $\beta$, tumour necrosis factor- $\alpha$ and leukotriene B4, which helped combat inflammatory responses. Moreover, butyrate treatment exerted remarkable positive influences that mediate an
\end{abstract}

Correspondence to: Dr Fangyan Wang, Department of Pathophysiology, School of Basic Medical Science, Wenzhou Medical University, 1 Central North Road, Wenzhou, Zhejiang 325000, P.R. China

E-mail: wzyxywfy@126.com

Dr Changlong Xu, Department of Gastroenterology, The Second Affiliated Hospital and Yuying Children's Hospital of Wenzhou Medical University, 109 Xueyuan West Road, Wenzhou, Zhejiang 325000, P.R. China

E-mail: xchlong@163.com

${ }^{*}$ Contributed equally

Key words: butyrate, gastric mucosal injury, inflammation, apoptosis, oxidation, therapy increase in 6-keto-PGF-1 $\alpha$ (a degradation product of prostacyclin), trefoil factor 2, MUC5AC and fibroblast growth factor-7 levels to promote gastric mucosal repair. The expression of specific receptor GPR109A for butyrate was upregulated, with no significant difference noted in the expression of GPR43 or GPR41. Overall, the present findings revealed that butyrate exerted therapeutic effects by upregulating mucosal repair factors and stimulating protective responses against oxidation and inflammation. GPR109A may be the key receptor for butyrate therapy.

\section{Introduction}

Gastric mucosal injury is considered a significant contributor to gastric cancer, with high incidence and recurrence rates $(1,2)$. Gastric acid acts as a chemical barrier in the stomach that kills foreign bacteria and protects from potential infections caused by pathogenic bacteria, which helps maintain homeostasis in gut microbiota. However, excessive gastric acid is a major risk factor for gastric mucosal injury $(3,4)$. Since proton pump inhibitors (PPIs) remarkably inhibit gastric acid secretion, their wide application is an important and plausible therapeutic approach for gastric mucosa lesions (5-7). However, the use of PPIs did not result in the expected fall in incidence rates of gastric cancer, and gastric cancer remains a great threat to humans worldwide (8-10). A study reported that the damaged gastric mucosa did not fully recover during PPIs treatment and was prone to recurrent gastric mucosal injury, which could lead to gastric cancer (11). Therefore, new therapies for gastric mucosal repair need to be urgently identified.

Butyrate is one of the most abundant short-chain fatty acids (SCFAs), produced by bacterial fermentation of dietary fibres in the colon, that are essential to maintain an intact digestive tract mucosa and prevent inflammatory bowel disease (IBD) development and carcinogenesis $(12,13)$. Butyrate serves as a critical energy source and is estimated to provide $70 \%$ of the total energy supply to intestinal epithelial cells. Butyrate combines with GPR109A, GPR43 and GPR41 and activates signalling pathways $(13,14)$. Butyrate reportedly attenuated inflammation in murine IBD models, and its effect could be 
dismissed in GPR $109 \mathrm{~A}^{-/-}$mice $(15,16)$. GPR43 $3^{-/}(17,18)$ and GPR $41^{-/-}$animals $(19,20)$ exhibited similar outcomes, showing that mucosal repairs were counteracted and inflammatory response was not decreased.

Most studies on butyrate were dedicated to its effects on the intestine, whereas few paid attention to its effects in the stomach. The response of gastric mucosa to butyrate is possibly similar to that of the intestine, considering the high embryonic homologies between the two organs. In previous experiments, mice that received butyrate administration beforehand were less likely to be afflicted with severe ethanol-induced acute gastric mucosal lesions (21). Nevertheless, whether butyrate has a healing effect on chronic gastric mucosal lesions and the precise pathways mediating this effect remain unclear.

In a previous study, gastric mucosal damage with ulcer formation induced by a local injection of acid was similar to human chronic gastric ulcer (GU) lesions in terms of morphological, histological and clinical characteristics (22). This classic chronic GU model (23) was used in the present study to determine the therapeutic effects of butyrate on chronic gastric mucosal injury and the mechanisms thus involved.

\section{Materials and methods}

Reagents. Butyrate sodium (cat. no. B5887) was obtained from Sigma-Aldrich (Merck KGaA). Detection kits for hematoxylin and eosin (HE; cat. no. D006-1-1) staining, superoxide dismutase (SOD; cat. no. A001-3-1) and catalase (CAT; cat. no. A007-1-1) were purchased from Nanjing Jiancheng Bioengineering Institute. Kits for malondialdehyde (MDA; cat. no. S0131S) and bicinchoninic acid (BCA; cat. no. P0011) protein assays were purchased from Beyotime Institute of Biotechnology. Enzyme-linked immunosorbent assay (ELISA) kits for mouse cytokines including interleukin-1 $\beta$ (IL-1 $\beta$; cat. no. F10770), tumour necrosis factor- $\alpha$ (TNF- $\alpha$; cat. no. F11630), leukotriene B4 (LTB ; cat. no. F10961) and 6-keto-PGF-1 $\alpha$ (cat. no. F11422) were obtained from Westang Biotech Co., Ltd. Primary antibodies against BAX (cat. no. bs-0127R) and GPR43 (cat. no. bs-23785R) were purchased from Beijing Biosynthesis Biotechnology Co., Ltd., and those for GPR41 (cat. no. BS5750) and GPR109A (cat. no. BS72723) were purchased from Bioworld Technology, Inc. PrimeScript ${ }^{\mathrm{TM}}$ RT reagent kit (cat. no. RR047Q) for reverse transcription and TB Green ${ }^{\circledR}$ Premix Ex Taq ${ }^{\mathrm{TM}}$ (cat. no. SR4110) were purchased from Takara Bio, Inc.

Animals. Male ICR mice were obtained from the Experimental Animal Center of Wenzhou Medical University (Wenzhou, China) and housed in specific pathogen-free animal quarters under a 12-h light-dark cycle. The mice were given free access to tap water and food. All animal procedures were performed in accordance with the guidelines of the Animal Ethics Committee of Wenzhou Medical University.

GU model and grouping. GU was induced experimentally in mice according to a method described by Mizuno et al (22), with modifications. The mice were placed supine on rat plates after overnight fasting and anesthetized by intraperitoneal injection of $50 \mathrm{mg} / \mathrm{kg}$ pentobarbital. The abdomen was sterilised with alcohol. A median incision of $\sim 2-3 \mathrm{~cm}$ was made along the midline. Diluted hydrochloric acid $(\mathrm{pH}=1 ; 10 \mu \mathrm{l})$ was then injected into the subserosa of the anterior wall at the lesser curvature of the stomach using a syringe. Later, the stomach was gently placed back into the abdomen, followed by suturing of the abdominal wall. The incision was sterilised again with alcohol, and the mice were placed back in cages after awakening. In control mice, the abdomen was opened and sutured without any injection.

Laparotomy was performed again 3 days after the operation, and mice with typical local ulcers were regarded as successful models. They were randomly divided into the sham, model and butyrate groups, with 10 mice in each group. The butyrate group mice were administered with $400 \mathrm{mg} / \mathrm{kg}$ butyrate intragastrically for 7 days. No mice was euthanized due to a 20-\% weight loss or debilitating signs, including reduced mobility, ruffled fur, hunched gait, inactivity or difficulty with eating and drinking. After 7 days, all mice were euthanized using sodium pentobarbital (150 mg/kg, intraperitoneal). Gastric tissues were subsequently obtained.

Histopathological observation of $G U$. Gastric tissues were collected, fixed in $10 \%$ buffered formalin at $4^{\circ} \mathrm{C}$ for $48 \mathrm{~h}$, dehydrated in an ascending ethanol followed by two xylene treatments. The samples were embedded in paraffin and the tissues were cut into 5- $\mu \mathrm{m}$ thick sections. The sections were subsequently deparaffinized in xylene and rehydrated with a descending ethanol gradient. The sections were and stained with haematoxylin for $5 \mathrm{~min}$ at $37^{\circ} \mathrm{C}$ and $1 \%$ eosin for $3 \mathrm{~min}$ at $37^{\circ} \mathrm{C}$. All gastric sections were observed under a light microscope (magnification, $\mathrm{x} 200$ ).

Immunohistochemical (IHC) analysis. From gastric tissue blocks, $5-\mu \mathrm{m}$ sections were deparaffinised, rehydrated and washed in distilled water three times. Antigen retrieval was achieved by using high pressure in citrate buffer $(\mathrm{pH}=6.0$; cat. no. C1010-2L; Beijing Solarbio Science \& Technology Co., Ltd.) at $110^{\circ} \mathrm{C}$ for $2 \mathrm{~min}$. They were then blocked with 5\% goat serum (Zhongshan Jinqiao Biotechnology Co., Ltd., OriGene Technologies, Inc.) for $30 \mathrm{~min}$ at $37^{\circ} \mathrm{C}$. Primary antibodies against BAX, GPR109A, GPR43 and GPR41 were diluted with PBST to a dilution of 1:200. Sections were covered with primary antibodies at $4^{\circ} \mathrm{C}$ overnight. The bound antibody was developed with diaminobenzidine using a Dako REAL Envision staining kit (cat. no. K5007; Agilent Technologies, Inc.) according to the manufacturer's instructions. The sections were soaked with haematoxylin for $5 \mathrm{~min}$ at room temperature, hydrochloric alcohol for $5 \mathrm{sec}$, PBS $(\mathrm{pH}=7.4)$ for $10 \mathrm{sec}$. Stained sections were examined under a light microscope (magnification, x200) by ZY and JXW.

Determination of MDA levels, and SOD and CAT activities. MDA levels and total SOD and CAT activities in gastric tissues were determined using thiobarbituric acid, xanthine oxidase and ammonium molybdate, respectively. Absorbance was detected using a 722N spectrophotometer (Scientific Instrument Co., Ltd). Procedures were performed according to the instructions provided for each kit.

ELISA for cytokines. IL-1 $\beta$, TNF- $\alpha, \mathrm{LTB}_{4}$ and 6-keto-PGF-1 $\alpha$ levels in GU tissues were determined using commercially 
Table I. Specific primers used for amplification of targeted genes.

\begin{tabular}{lll}
\hline Gene name & \multicolumn{1}{c}{ Forward primer } & \multicolumn{1}{c}{ Reverse primer } \\
\hline BAX & 5'-ACCAAGAAGCTGAGCGAGTG-3' & 5'-CCCAGTTGAAGTTGCCATCA-3' \\
Caspase 3 & 5'-ATGGGAGCAAGTCAGTGGAC-3' & 5'-GTCCACATCCGTACCAGAGC-3' \\
TFF1 & 5'-AAGGTGATCTGTGTCCTCGC-3' & 5'-AAACAGCAACCTCTCTCCGT-3' \\
TFF2 & 5'-CGGAGCAGTGTGTCATGGAA-3' & 5'-AAGAAACACCAGGGCACTTCA-3' \\
TFF3 & 5'-GCCCTCTGGCTAATGCTGTT-3' & 5'-CGGTTGTTACACTGCTCCGA-3' \\
MUC5AC & 5'-GTTCACTCTACCACTCCCTGC-3' & 5'-CAATCCTGGCTACACATCGC-3' \\
FGF7 & 5'-CGTGGCAGTTGGAATTGTGG-3' & 5'-AGGCAACGAACATTTCCCCT-3' \\
GPR109A & 5'-TACCACCCTTAGCTTTACCT-3' & 5'-CCTGGAATACTTCTGGTTGT-3' \\
GPR43 & 5'-GGTGTGCTTTGGACCCTACA-3' & 5'-CTGTCTCTTTGGCTCCCCTG-3' \\
GPR41 & 5'-TGAGCATCGAACGTTTTCTG-3' & 5'-CCAGGTAGCAGGTTCCATTG-3' \\
GAPDH & 5'-AGGTCGGTGTGAACGGATTTG-3' & 5'-GGGGTCGTTGATGGCAACA-3'
\end{tabular}

TFF, trefoil factors; FGF, fibroblast growth factor; GPR, G protein-coupled receptor.

available ELISA kits as per the corresponding manufacturer's protocol. Briefly, GU tissue homogenates were pipetted into 96-well plates coated with the primary antibodies and incubated for $3 \mathrm{~h}$ at $37^{\circ} \mathrm{C}$. Biotin conjugate was then added for incubation for $45 \mathrm{~min}$ at room temperature after washing. Streptavidin-horseradish peroxidase was incubated for $45 \mathrm{~min}$ at $37^{\circ} \mathrm{C}$ after washing nonspecific binding. Then, a chromogen was pipetted into each well for absorbance at $450 \mathrm{~nm}$. IL-1 $\beta$, TNF- $\alpha$, LTB $_{4}$ and 6-keto-PGF-1 $\alpha$ levels were calculated using standard curves according to the ELISA kit instructions.

Reverse transcription-quantitative polymerase PCR analysis. Total RNA was isolated from cultured cells using TRIzon reagent (cat. no. CW0580S; Beijing ComWin Biotech Co., Ltd.) as per the manufacturer's protocols. Reverse transcription was performed using the PrimeScript ${ }^{\mathrm{TM}} \mathrm{RT}$ reagent kit. The thermocycling condition was as follows: $37^{\circ} \mathrm{C}$ for $15 \mathrm{~min}$; followed by $85^{\circ} \mathrm{C}$ for $5 \mathrm{sec}$ and then $4^{\circ} \mathrm{C}$ for storage. qPCRs were prepared using SYBR Green on a Prism 7500 Sequence Detector (Thermo Fisher Scientific, Inc.). The thermocycling condition was as follows: Initial denaturation at $95^{\circ} \mathrm{C}$ for $10 \mathrm{~min}$; followed by 40 cycles of $95^{\circ} \mathrm{C}$ for $15 \mathrm{sec}, 60^{\circ} \mathrm{C}$ for $45 \mathrm{sec}$ and then $95^{\circ} \mathrm{C}$ for $15 \mathrm{sec}$. mRNA expression levels of BAX, Caspase-3, trefoil factors (TFFs) 1-3, MUC5AC, fibroblast growth factor-7 (FGF7), GPR109A, GPR43 and GPR41 were normalised to levels of GAPDH. The $2^{-\Delta \Delta \mathrm{Cq}}$ method was used for relative quantification (24). Sequences for qPCR primers for all targeted genes are listed in Table I.

Statistical analysis. All experimental data are expressed as mean \pm SD. Mean differences were compared with one-way ANOVA followed by multiple comparison by Bonferroni test. $\mathrm{P}<0.05$ was considered to indicate a statistically significant difference.

\section{Results}

Butyrate alleviates pathological damage to gastric mucosa in mice. Conventional HE staining was used to examine the pathological changes in different groups. Histological examination in the sham group demonstrated that the epithelial lining was intact and glandular cavities were clear; furthermore, there was no inflammatory cell infiltration in the gastric mucosa. Necrotic tissue was observed on the mucosal ulcer surface in the model group. There was granulation hyperplasia with inflammatory cell infiltration; furthermore, hyperaemia, oedema and neovascularisation were observed surrounding the ulcer. Butyrate treatment significantly attenuated the gastric mucosal damage induced by acid injection. The gastric mucosal structure appeared intact with regular hyperplastic glands, and inflammatory cells were occasionally found under the mucosa (Fig. 1A).

IHC results suggested that BAX was strongly and positively expressed in the GU group compared with that in control animals. Butyrate treatment significantly counteracted such changes (Fig. 1B). qPCR results suggested that butyrate treatment decreased BAX and caspase-3 expression levels (Fig. 1C), and this finding was consistent with the IHC analysis results.

Butyrate ameliorated oxidative stress in $G U$. It is well established that oxidative stress plays an important role in GU formation. SOD and CAT activities, as well as MDA levels in GU tissues, were used to measure oxidative stress levels in the various groups (Fig. 2). SOD and CAT activities were significantly lower and MDA levels were significantly higher $(\mathrm{P}<0.01)$ in the model group compared with other groups. Butyrate treatment significantly attenuated these changes (Fig. 2; $\mathrm{P}<0.01$ ), suggesting the mitigating effect of butyrate on oxidative stress in GU.

Butyrate attenuates inflammation in $G U$. Cytokine levels were measured to investigate the underlying mechanisms of the therapeutic effects of butyrate on gastric mucosal lesions because of the involvement of excessive inflammatory responses in $\mathrm{GU}$ pathogenesis. Changes in TNF- $\alpha$, IL-1 $\beta$ and $\mathrm{LTB}_{4}$ levels in gastric tissues of the various groups are shown in Fig. 3; the levels of these cytokines were significantly higher in the model group compared with the other groups. Butyrate treatment 

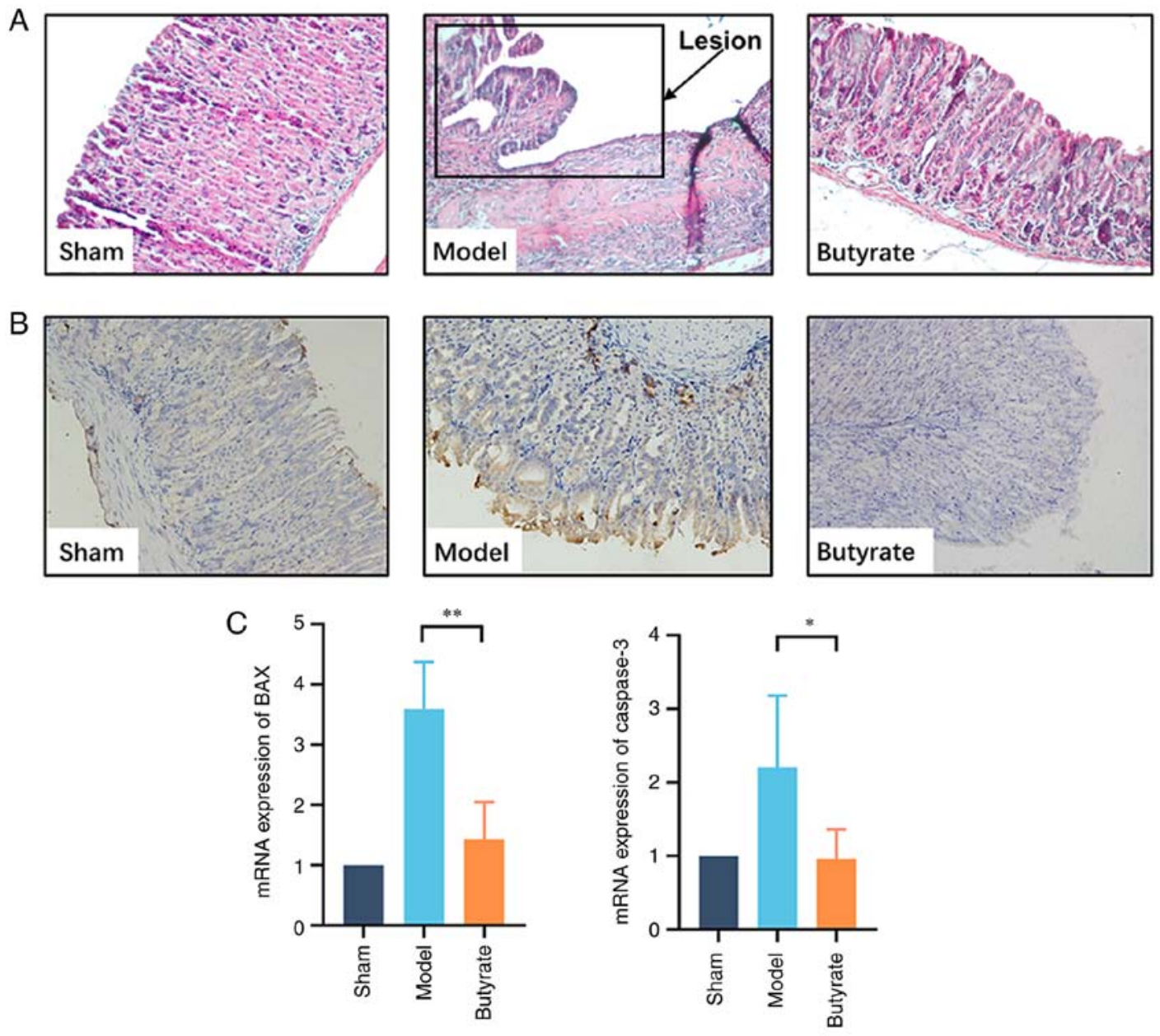

Figure 1. Therapeutic effects of butyrate on chronic GU in mice. (A) Histological assessment. Gastric tissues from GU (n=4/group) were fixed with $4 \%$ paraformaldehyde and sectioned to prepare for hematoxylin and eosin staining (magnification, x200). (B) Immunohistochemical analysis for BAX. Gastric tissue samples were fixed and sectioned for staining using primary antibody against BAX. Brown granules in cells were considered to indicate positive results. (C) qPCR to determine the expression of genes encoding BAX and Caspase-3 in the gastric tissues from GU location. The total RNA of gastric samples was extracted for detecting the mRNA levels of targeted genes via qPCR. Results indicate mean $\pm \mathrm{SD}$. ${ }^{*} \mathrm{P}<0.05 ;{ }^{* *} \mathrm{P}<0.01$. GU, gastric ulcer; qPCR, quantitative polymerase chain reaction.
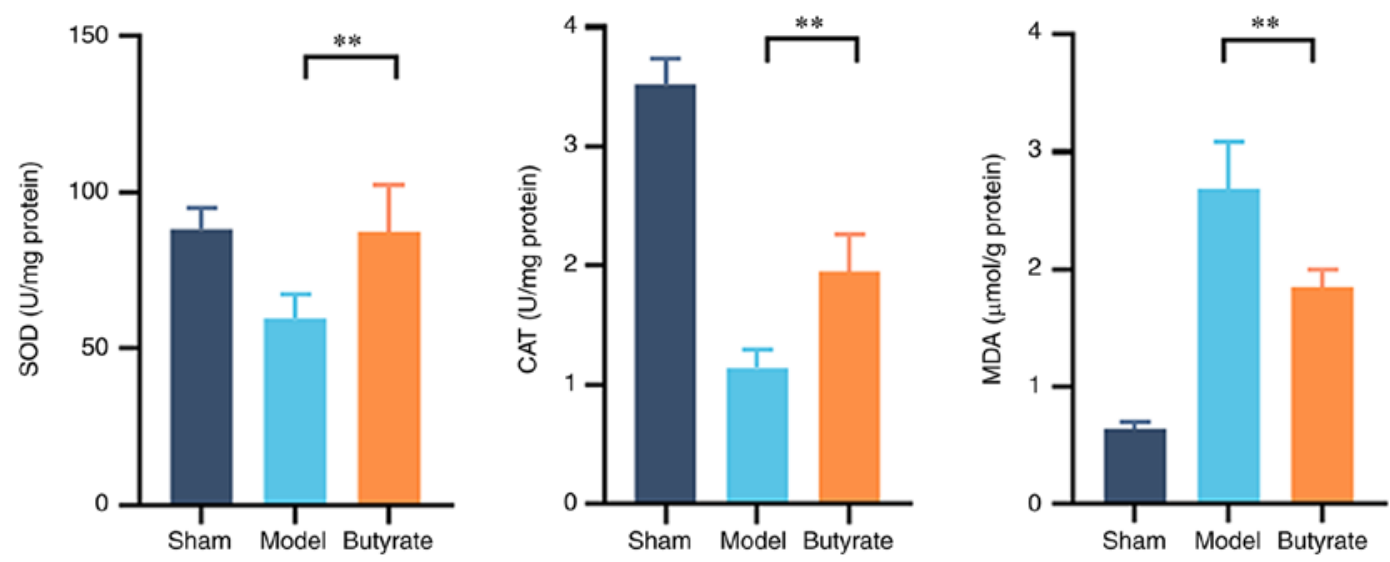

Figure 2. Changes in SOD and CAT activities and MDA levels in different groups ( $\mathrm{n}=4-6 /$ group). The gastric tissues samples from GU location were homogenised for determining SOD and CAT activities and MDA levels. Proteins in the gastric samples were quantified via BCA assay, which was used to normalise the tested parameters in gastric tissue. Data are expressed as mean $\pm \mathrm{SD} .{ }^{* *} \mathrm{P}<0.01$. SOD, superoxide dismutase; CAT, catalase; MDA, malondialdehyde.

decreased the elevation in the levels of these pro-inflammatory cytokines ( $\mathrm{P}<0.01 ;$ Fig. 3). This suggests that butyrate attenuates the excessive inflammation involved in the development of gastric mucosal ulcers induced by erosion due to acid in mice. 

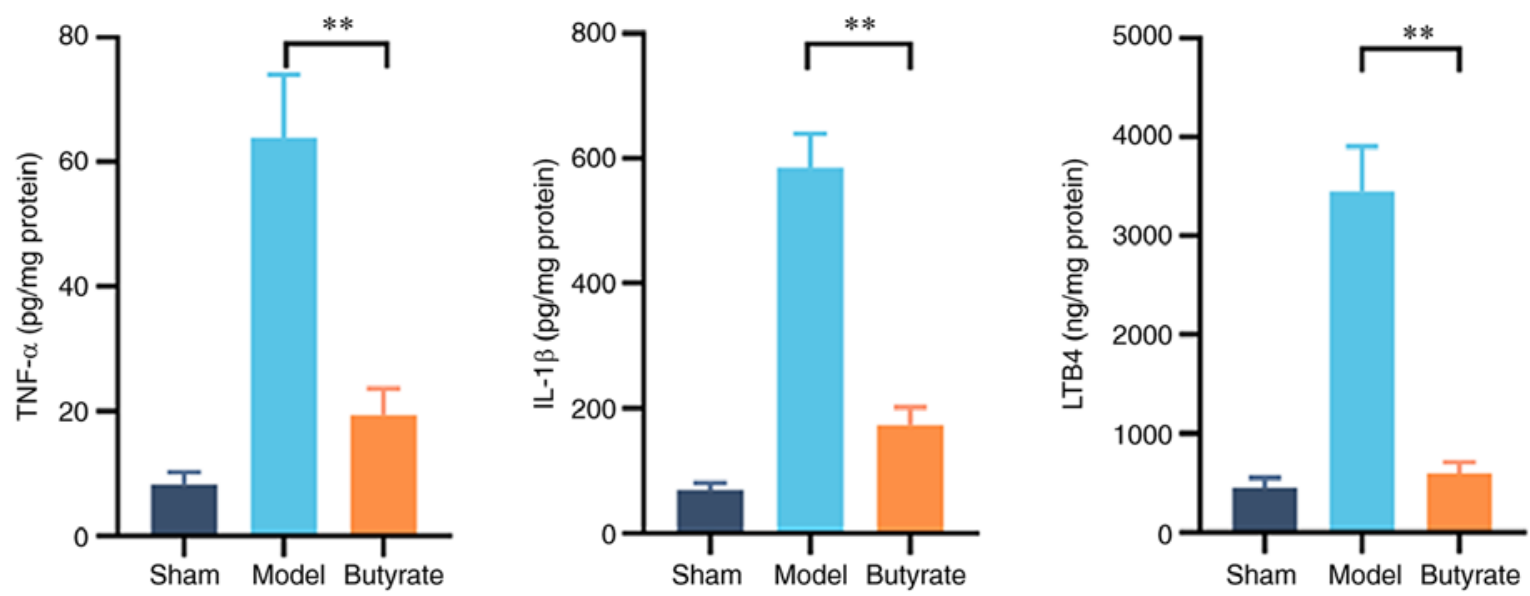

Figure 3. Changes in the levels of pro-inflammatory cytokines in different groups ( $\mathrm{n}=4-6 /$ group). Gastric tissues were collected for enzyme-linked immunosorbent assay after butyrate treatment. Proteins in the gastric samples were quantitated via BCA assay, which was used to normalise the tested parameters in gastric tissue. Results represent mean $\pm \mathrm{SD}$. ${ }^{* *} \mathrm{P}<0.01$. TNF, tumor necrosis factor; IL, interleukin; LTB4, leukotriene B4.
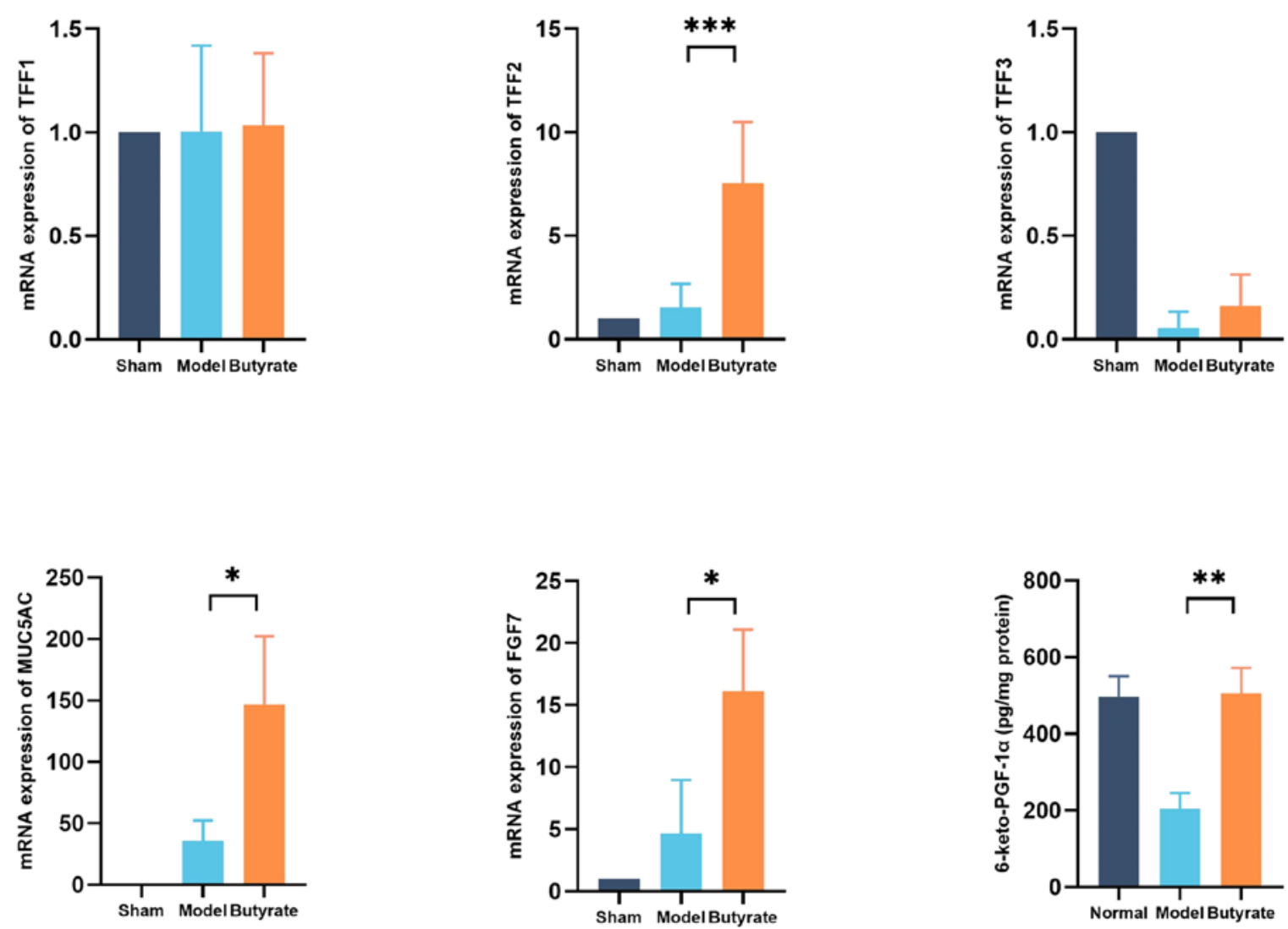

Figure 4. Changes in parameters reflecting gastric mucosal repair in different groups ( $\mathrm{n}=4$-6/group). The total RNA was extracted for measuring mRNA levels of targeted genes encoding MUC5AC, TFFs1-3 and FGF7 using quantitative PCR. Enzyme-linked immunosorbent assay was used to measure 6-keto-PGF-1 $\alpha$ levels. Results represent mean $\pm \mathrm{SD} .{ }^{*} \mathrm{P}<0.05 ;{ }^{* *} \mathrm{P}<0.01 ;{ }^{* * *} \mathrm{P}<0.001$. TFF, trefoil factors; FGF, fibroblast growth factor; PGF, prostaglandin F.

Butyrate promotes gastric mucosal repair. TFFs1-3, MUC5AC and FGF7 are crucial for gastric mucosal repair. qPCR was performed to determine the changes in expression levels of these proteins in the various groups. Butyrate significantly increased the expression levels of genes encoding MUC5AC, FGF7 and TFF2 proteins $(\mathrm{P}<0.05)$, but not of those encoding TFF1 or TFF3 proteins, in gastric tissues (Fig. 4). Prostacyclin (PGI2) is important for maintaining gastric mucosal defences. The levels of 6-keto-PGF-1 $\alpha$ (a PGI2 metabolite) were measured, which reflect gastric mucosal repair; were significantly higher in butyrate-treated mice compared with those of the model mice $(\mathrm{P}<0.01 ;$ Fig. 4).

Butyrate upregulates GPR109A expression. Given that SCFA receptors, including GPR109A, GPR43 and GPR41, are 

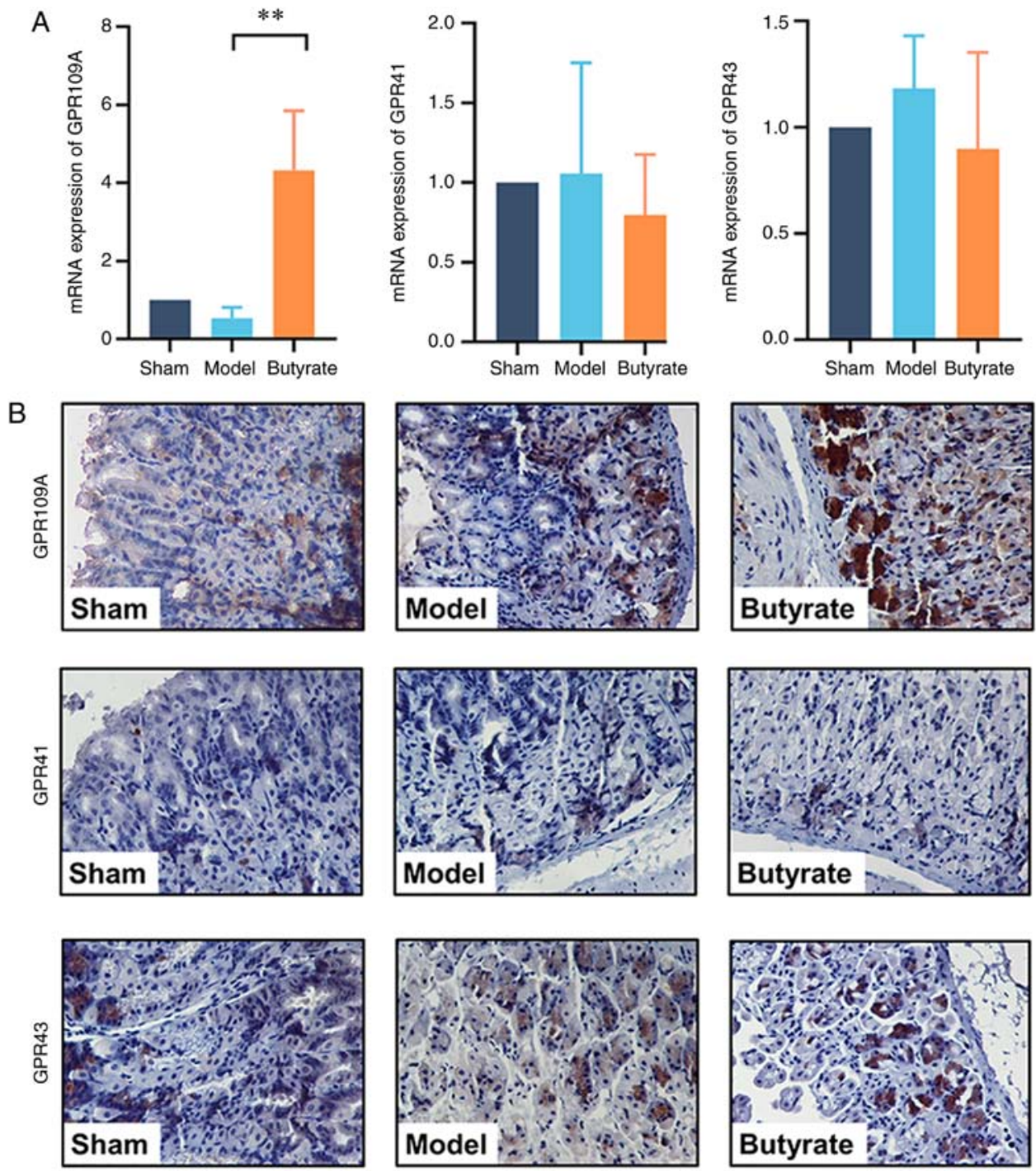

Figure 5. Expression levels of SCFA receptors GPR109A, GPR43 and GPR41 in the various groups (n=4-6/group). (A) qPCR for determining the expression of genes encoding GPR109A, GPR43 and GPR41. The total RNA was extracted for detection of mRNA levels of targeted genes encoding GPR109A, GPR43 and GPR41 via qPCR. Results indicate mean \pm SD. ${ }^{* *} \mathrm{P}<0.01$. (B) Immunohistochemical analysis of GPR109A, GPR 43 and GPR41. Gastric samples were fixed and sectioned for staining using primary antibody against GPR109A, GPR43 and GPR41. Brown granules in cells indicate positive results. qPCR, quantitative polymerase chain reaction. GPR, G protein-coupled receptor; SCFA, short-chain fatty acid.

important for the biological function of SCFAs, the expression levels of these receptors were tested to determine the signalling mechanisms underlying the therapeutic effects of butyrate. qPCR results showed that the expression of GPR109A, but not of GPR43 or GPR41, was upregulated by butyrate treatment $(\mathrm{P}<0.01$; Fig. 5A). Consistent with these findings, IHC analysis showed that GPR109A was strongly positively expressed in the butyrate group compared with that in the GU mice. However, butyrate treatment did not change GPR43 or GPR41 expression levels (Fig. 5B).

\section{Discussion}

Nonsteroidal anti-inflammatory drugs and Helicobacter pylori infection are the leading factors that impair gastric mucosa defences and give rise to GUs; however, the acid corrosive effect on gastric mucosa is the basic factor contributing to GU pathogenesis (1). For this reason, the chronic GU model is traditionally established using a local injection of $20 \%$ acetic acid under the mucosal lumen to imitate acid corrosion-induced GU (22). Due to the protective effect of SCFA acetate on gastric mucosa observed in a previous study (25), diluted hydrochloric acid $(\mathrm{pH}=1)$, the main component of gastric acid, was used instead of acetic acid, to build the GU model in the present study. The diameter of a GU usually ranges from 0.4 to $0.8 \mathrm{~cm}$, depending directly on the concentration and dosage of the acid used in this model. Based on a preliminary experiment, $10 \mu$ l hydrochloric acid $(\mathrm{pH}=1)$ was chosen as suitable for the chronic GU establishment.

It was difficult to maintain an accurate depth of acid injection for $\mathrm{GU}$ formation during the animal operation. Therefore, the abdomen was opened to select the mice with GU 3 days after the acid injection for the experiment. In the model group, pathological examination showed that acid injection induced a series of typical changes that occur during ulcer development, including local mucosal necrosis 


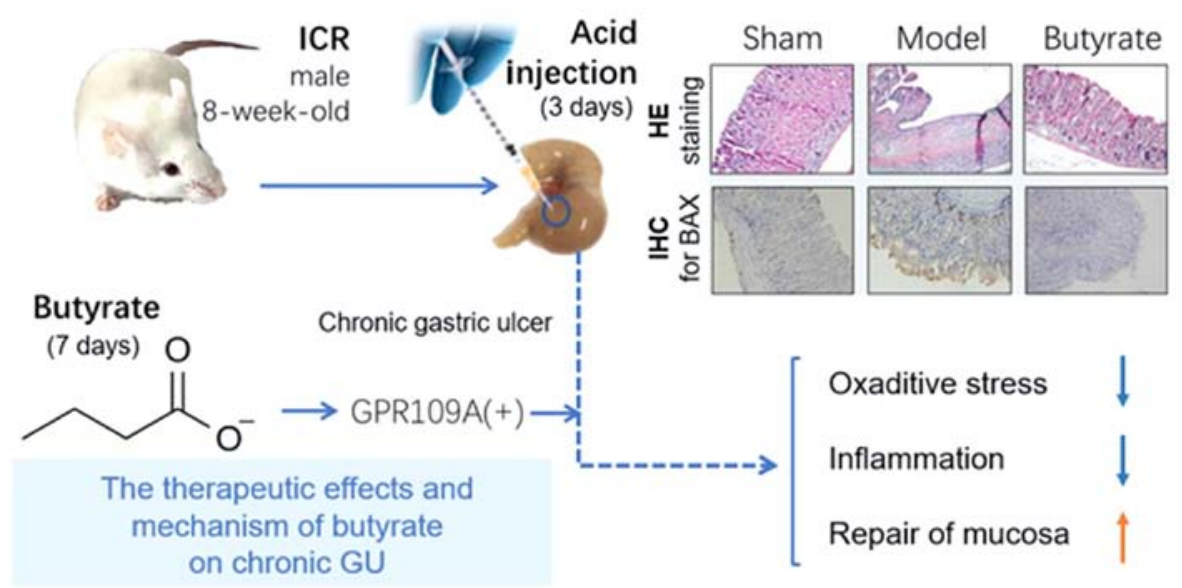

Figure 6. Schematic diagram of the mechanism. Butyrate treatment heals chronic GU via its anti-inflammatory and anti-oxidative effects and via promoting mucosal repair. GPR109A may be the key receptor for the therapeutic effects of butyrate. HE, hematoxylin and eosin; IHC, Immunohistochemistry; GU gastric ulcer.

and submucosal granulation tissue formation, similar to human chronic ulcer. This suggests that the GU model was successfully constructed.

Since excessive gastric acid secretion contributes to mucosal injury, its proper inhibition lays a foundation on current GU treatment. However, despite the extensive PPIs usage $(26,27)$, the recurrence of GU remains high. Therefore, experimental agents with mucosal repairing ability were investigated. Butyrate is an important metabolite from indigestive fibers fermented by gut microbiota. When orally administrated, butyrate is mainly absorbed by digestive mucosa and thereby elevates the expression of tight junction proteins MUC3, MUC5B, ZO-1 and Occludin to protect the mucosa (28-31). It is noteworthy that butyrate prompts the repair and recovery in intestinal mucosa $(13,21,30)$, while its effect on gastric acid secretion has not been reported yet. Hence, corresponding experiments were conducted to uncover that butyrate pretreatment protected gastric mucosa from ethanol-induced lesions. Therefore, it is postulated that butyrate prompts recovery in gastric mucosa similar to that in intestine on a distinct basis of its remarkable ability of mucosal repair, rather than that of acid secretion inhibition.

Butyrate is a preferable energy source for human intestinal epithelial cells, and has been widely used as a food additive (32). Egorin et al (33) reported the maximum tolerated dose of sodium butyrate in mice as $1.25 \mathrm{~g} / \mathrm{kg}$ in a study of sodium butyrate plasma pharmacokinetics, which was over triple times higher than $400 \mathrm{mg} / \mathrm{kg}$ used in the present study. Liang et al (34) found that $400 \mathrm{mg} / \mathrm{kg}$ sodium butyrate, equivalent to $640 \mathrm{mg} / \mathrm{kg}$ for mice, could defend severe burn-induced remote acute lung injury in rats. Therefore, the dose of butyrate used in the present study's experimental mice ( $400 \mathrm{mg} / \mathrm{kg}$ ), equal to $44 \mathrm{mg} / \mathrm{kg}$ for human, was of easy access and less severe dose-dependent side effects.

In the present study, it was found that oral butyrate significantly alleviated the pathological damage to gastric mucosa in mice. The butyrate group exhibited less necrotic tissues and more proliferative glands with regular arrangement. The physical condition of the mice improved following treatment with butyrate. The mice showed inactivity, food intake reduction, fluffy-coat formation and decreased body weight and passed shapeless faeces after modelling; however, these symptoms were significantly alleviated following butyrate treatment. Mice feeding, activity levels and stool appearance were normal, and their weight also increased on the seventh day. Given that butyrate is produced by probiotic microbiota, most of the previous studies focused mainly on intestinal diseases $(35,36)$. The present study findings suggest that butyrate heals chronic gastric mucosal lesions.

Oxidative stress is one of the most important factors contributing to the pathological development of GU. The anti-oxidants SOD and CAT attenuate oxidative stress. In the studies on GU, it was found that SOD and CAT activities were significantly decreased after modelling $(25,37)$. Butyrate was shown to increase the anti-oxidative capacity in rats (38) and HepG2 cells (39). The present data suggest that the levels of oxidative product MDA in gastric tissues were increased and activities of SOD and CAT were decreased in the model group, whereas butyrate treatment attenuated the changes in these parameters, thereby protecting against oxidative damage.

Excessive inflammation is a crucial factor in GU formation. Levels of pro-inflammatory factors IL-1 $\beta$, TNF- $\alpha$ and $\mathrm{LTB}_{4}$ were elevated in the model mice, whereas this elevation in levels was substantially decreased by butyrate treatment. The anti-inflammatory effect of butyrate has been extensively studied in various fields $(16,17,36)$. Some studies reported that butyrate inhibited the nuclear factor $\kappa \mathrm{B}$ signal pathway to prevent the intestinal epithelial injury caused by inflammation (40-42). SCFA-specific receptors GPR43, GPR41 and particularly GPR109A, mediate the anti-inflammatory effects of SCFAs $(15,18,20)$. The present data showed that the expression of GPR109A, but not of GPR43 or GPR41, was significantly upregulated by butyrate treatment, suggesting GPR109A to be the key receptor of butyrate for mediating its gastric protective effect. Nevertheless, the underlying mechanisms remain to be investigated in future studies.

In the present study, TFFs1-3, MUC5AC and FGF7 levels were determined, which reflect gastric mucosal repair. Previously, TFFs1-3 (43-45) and FGF7 (46) were shown to 
promote gastric mucosal repair. It was found that butyrate treatment significantly upregulated TFF2, MUC5AC and FGF7 expression levels. Butyrate is necessary for the nutrition of the intestinal epithelium to maintain mucosal integrity (13). In the present study, the therapeutic effect of butyrate on GU was investigated. Combined with the analysis for the special receptors of SCFAs, the data suggest that butyrate regulates gene expression via the GPR109A signalling pathway. Nevertheless, it has been well documented that butyrate acts as a histone deacetylase inhibitor (HDACi) to regulate gene expression by increasing acetylation modification of histones (47-49). It is noteworthy that because of the Warburg effect, butyrate concentration increased so that it acts as an HDACi in cancerous cells, but it entered the tricarboxylic acid cycle at physiological levels to act as a substrate for energy metabolism (50). In future experiments, the detailed mechanism underlying the therapeutic effects of butyrate will be validated.

It was reported that GPR109A mediates cyclooxygenase (COX) activation to increase prostanoid formation $(51,52)$. COXs are important for maintaining the gastric mucosal barrier (53). The present results suggest that butyrate promotes PGI2 production, reflected by 6 -keto-PGF-1 $\alpha$ levels, and significantly decreased $\mathrm{LTB}_{4}$ levels. Thus, butyrate may exert its therapeutic effects on GUs via arachidonic acid metabolic pathway regulation.

In conclusion, the therapeutic effect of butyrate on chronic GUs was identified via anti-oxidation, anti-inflammation and promotion of gastric mucosal repair; the effect may be mediated by the GPR109A receptor. The hypothesis regarding the therapeutic mechanism of butyrate is presented in Fig. 6.

\section{Acknowledgements}

Not applicable.

\section{Funding}

The present study was supported by grants from the Science and Technology Department of Zhejiang (grant nos. 2017C33068, LY20H180010 and LGF20H070003), the Medical and Health Research Project Grant of Zhejiang Province of China (grant no. Y2019317606) and the Technology Bureau of Wenzhou (grant no. Y20180142 and Y20190060). The funders had no role in the study design, data collection and analysis, decision to publish, or preparation of the manuscript.

\section{Availability of data and materials}

The datasets used and/or analyzed during the current study are available on reasonable request from the corresponding author.

\section{Authors' contributions}

FYW and CLX conceived and designed the study. YZ, XWJ, JJC, JKC, YYF, JWH, RG, JHZ, QHZ and AC performed the experiments. YZ and XWJ authenticated the raw data in this study. YPH participated in drafting the manuscript together with YZ and XWJ, and performed data analysis with YZ, XWJ and JKC. YZ and XWJ wrote up the manuscript. FYW,
CLX and YPH revised the critically manuscript for important intellectual content and finally approved the version to be published. All authors have read and agreed to the published version of the manuscript.

\section{Ethics approval and consent to participate}

Experimental procedures and the Animal Use and Care protocols were approved by the Ethics Committee of Wenzhou Medical University (approval no. wydw2012-0109; Wenzhou, China).

\section{Patient consent for publication}

Not applicable.

\section{Competing interests}

The authors declare that they have no competing interests.

\section{References}

1. Graham DY: History of Helicobacter pylori, duodenal ulcer, gastric ulcer and gastric cancer. World J Gastroenterol 20: 5191-5204, 2014.

2. Waldum HL, Kleveland PM and Sordal OF: Helicobacter pylori and gastric acid: An intimate and reciprocal relationship. Therap Adv Gastroenterol 9: 836-844, 2016.

3. Adeniyi OS, Emikpe BO and Olaleye SB: Accelerated gastric ulcer healing in thyroxine-treated rats: Roles of gastric acid, mucus, and inflammatory response. Can J Physiol Pharmacol 96: 597-602, 2018.

4. Brzozowski T, Magierowska K, Magierowski M, Ptak-Belowska A, Pajdo R, Kwiecien S, Olszanecki R and Korbut R: Recent advances in the gastric mucosal protection against stress-induced gastric lesions. Importance of renin-angiotensin vasoactive metabolites, gaseous mediators and appetite peptides. Curr Pharm Des 23: 3910-3922, 2017.

5. Yu LY, Sun LN, Zhang XH, Li YQ, Yu L, Yuan ZQ, Meng L, Zhang HW and Wang YQ: A review of the novel application and potential adverse effects of proton pump inhibitors. Adv Ther 34: 1070-1086, 2017

6. Yang X, Li Y, Sun Y, Zhang M, Guo C, Mirza IA and Li YQ: Vonoprazan: A novel and potent alternative in the treatment of acid-related diseases. Dig Dis Sci 63: 302-311, 2018.

7. Yamamoto O, Okada Y and Okabe S: Effects of a proton pump inhibitor, omeprazole, on gastric secretion and gastric and duodenal ulcers or erosions in rats. Dig Dis Sci 29: 394-401, 1984.

8. Yoon $\mathrm{H}$ and Kim N: Diagnosis and management of high risk group for gastric cancer. Gut Liver 9: 5-17, 2015.

9. Ang TL and Fock KM: Clinical epidemiology of gastric cancer. Singapore Med J 55: 621-628, 2014.

10. Yan S, Li B, Bai ZZ, Wu JQ, Xie DW, Ma YC, Ma XX, Zhao JH and Guo XJ: Clinical epidemiology of gastric cancer in hehuang valley of China: A 10-year epidemiological study of gastric cancer. World J Gastroenterol 20: 10486-10494, 2014.

11. Hansson LE, Nyren O, Hsing AW, Bergström R, Josefsson S, Chow WH, Fraumeni JF Jr and Adami HO: The risk of stomach cancer in patients with gastric or duodenal ulcer disease. N Engl J Med 335: 242-249, 1996.

12. Tedelind $\mathrm{S}$, Westberg $\mathrm{F}$, Kjerrulf $\mathrm{M}$ and Vidal $\mathrm{A}$ : Anti-inflammatory properties of the short-chain fatty acids acetate and propionate: A study with relevance to inflammatory bowel disease. World J Gastroenterol 13: 2826-2832, 2007.

13. Ploger S, Stumpff F, Penner GB, Schulzke JD, Gäbel G, Martens H, Shen Z, Günzel D and Aschenbach JR: Microbial butyrate and its role for barrier function in the gastrointestinal tract. Ann N Y Acad Sci 1258: 52-59, 2012.

14. Kimura I, Ichimura A, Ohue-Kitano R and Igarashi M: Free fatty acid receptors in health and disease. Physiol Rev 100: 171-210, 2020. 
15. Singh N, Gurav A, Sivaprakasam S, Brady E, Padia R, Shi H, Thangaraju M, Prasad PD, Manicassamy S, Munn DH, et al: Activation of Gpr109a, receptor for niacin and the commensal metabolite butyrate, suppresses colonic inflammation and carcinogenesis. Immunity 40: 128-139, 2014.

16. Chen G, Ran X, Li B, Li Y, He D, Huang B, Fu S, Liu J and Wang W: Sodium butyrate inhibits inflammation and maintains epithelium barrier integrity in a TNBS-induced inflammatory bowel disease mice model. EBioMedicine 30: 317-325, 2018

17. Pirozzi C, Francisco V, Guida FD, Gómez R, Lago F, Pino J, Meli R and Gualillo O: Butyrate modulates inflammation in chondrocytes via GPR43 receptor. Cell Physiol Biochem 51: 228-243, 2018.

18. Nakajima A, Nakatani A,Hasegawa S, Irie J, Ozawa K, Tsujimoto G Suganami T, Itoh $\mathrm{H}$ and Kimura I: The short chain fatty acid receptor GPR43 regulates inflammatory signals in adipose tissue M2-type macrophages. PLoS One 12: e0179696, 2017.

19. Lin HV, Frassetto A, Kowalik EJ Jr, Nawrocki AR, Lu MM, Kosinski JR, Hubert JA, Szeto D, Yao X, Forrest G and Marsh DJ: Butyrate and propionate protect against diet-induced obesity and regulate gut hormones via free fatty acid receptor 3-independent mechanisms. PLoS One 7: e35240, 2012.

20. Kim MH, Kang SG, Park JH, Yanagisawa $\mathrm{M}$ and $\mathrm{Kim} \mathrm{CH}$ : Short-chain fatty acids activate GPR41 and GPR43 on intestina epithelial cells to promote inflammatory responses in mice. Gastroenterology 145: 396-406 e391-310, 2013.

21. Liu J, Wang F, Luo H, Liu A, Li K, Li C and Jiang Y: Protective effect of butyrate against ethanol-induced gastric ulcers in mice by promoting the anti-inflammatory, anti-oxidant and mucosa defense mechanisms. Int Immunopharmacol 30: 179-187, 2016.

22. Mizuno H, Sakamoto C, Matsuda K, Wada K, Uchida T, Noguchi H, Akamatsu $\mathrm{T}$ and Kasuga M: Induction of cyclooxygenase 2 in gastric mucosal lesions and its inhibition by the specific antagonist delays healing in mice. Gastroenterology 112 : 387-397, 1997.

23. Toma W, Hiruma-Lima CA, Guerrero RO and Brito AR: Preliminary studies of mammea americana L. (Guttiferae) bark/latex extract point to an effective antiulcer effect on gastric ulcer models in mice. Phytomedicine 12: 345-350, 2005.

24. Livak KJ and Schmittgen TD: Analysis of relative gene expression data using real-time quantitative PCR and the 2(-Delta Delta C(T)) method. Methods 25: 402-408, 2001.

25. Liu J, Wang J, Shi Y, Su W, Chen J, Zhang Z, Wang G and Wang F: Short chain fatty acid acetate protects against ethanol-induced acute gastric mucosal lesion in mice. Biol Pharm Bull 40 : 1439-1446, 2017

26. Kangwan N, Park JM, Kim EH and Hahm KB: Quality of healing of gastric ulcers: Natural products beyond acid suppression. World J Gastrointest Pathophysiol 5: 40-47, 2014.

27. Tarnawski A, Douglass TG, Stachura J and Krause WJ: Quality of gastric ulcer healing: Histological and ultrastructural assessment. Aliment Pharmacol Ther 1 (5 Suppl): S79-S90, 1991.

28. Guilloteau P, Martin L, Eeckhaut V, Ducatelle R, Zabielski R and Van Immerseel F: From the gut to the peripheral tissues: The multiple effects of butyrate. Nutr Res Rev 23: 366-384, 2010.

29. Bloemen JG, Venema K, van de Poll MC, Olde Damink SW, Buurman WA and Dejong CH: Short chain fatty acids exchange across the gut and liver in humans measured at surgery. Clin Nutr 28: 657-661, 2009.

30. Gaudier E, Jarry A, Blottiere HM, de Coppet P, Buisine MP, Aubert JP, Laboisse C, Cherbut C and Hoebler C: Butyrate specifically modulates MUC gene expression in intestinal epithelial goblet cells deprived of glucose. Am J Physiol Gastrointest Liver Physiol 287: G1168-G1174, 2004.

31. Liang JB, Wang P, Feng YH, Huang YL, Wang FJ and Ren H: Effects of sodium butyrate on intestinal barrier of severe scald mice and the related mechanism. Zhonghua shao shang za zhi 36 : 48-53, 2020 (In Chinese).

32. Barcenilla A, Pryde SE, Martin JC, Duncan SH, Stewart CS, Henderson $C$ and Flint HJ: Phylogenetic relationships of butyrate-producing bacteria from the human gut. Appl Environ Microbiol 66: 1654-1661, 2000.

33. Egorin MJ, Yuan ZM, Sentz DL, Plaisance K and Eiseman JL: Plasma pharmacokinetics of butyrate after intravenous administration of sodium butyrate or oral administration of tributyrin or sodium butyrate to mice and rats. Cancer Chemother Pharmacol 43: 445-453, 1999.
34. Liang X, Wang RS, Wang F, Liu S, Guo F, Sun L, Wang YJ, Sun YX and Chen XL: Sodium butyrate protects against severe burn-induced remote acute lung injury in rats. PLoS One 8: e68786, 2013

35. Wong JM, de Souza R, Kendall CW, Emam A and Jenkins DJ: Colonic health: Fermentation and short chain fatty acids. J Clin Gastroenterol 40: 235-243, 2006.

36. Hijova $\mathrm{E}$ and Chmelarova A: Short chain fatty acids and colonic health. Bratisl Lek Listy 108: 354-358, 2007.

37. Wang FY, Liu JM, Luo HH, Liu AH and Jiang Y: Potential protective effects of clostridium butyricum on experimental gastric ulcers in mice. World J Gastroenterol 21: 8340-8351, 2015.

38. Lin Y, Fang ZF, Che LQ, Xu SY, Wu D, Wu CM and Wu XQ: Use of sodium butyrate as an alternative to dietary fiber: Effects on the embryonic development and anti-oxidative capacity of rats. PLoS One 9: e97838, 2014.

39. Xing X, Jiang Z, Tang X, Wang P, Li Y, Sun Y, Le G and Zou S: Sodium butyrate protects against oxidative stress in HepG2 cells through modulating Nrf2 pathway and mitochondrial function. J Physiol Biochem 73: 405-414, 2016.

40. Inan MS, Rasoulpour RJ, Yin L, Hubbard AK, Rosenberg DW and Giardina C: The luminal short-chain fatty acid butyrate modulates NF-kappaB activity in a human colonic epithelial cell line. Gastroenterology 118: 724-734, 2000.

41. Yin L, Laevsky G and Giardina C: Butyrate suppression of colonocyte NF-kappa B activation and cellular proteasome activity. J Biol Chem 276: 44641-44646, 2001.

42. Luhrs H, Gerke T, Muller JG, Melcher R, Schauber J, Boxberge F, Scheppach W and Menzel T: Butyrate inhibits NF-kappaB activation in lamina propria macrophages of patients with ulcerative colitis. Scand J Gastroenterol 37: 458-466, 2002.

43. Aziz RS, Siddiqua A, Shahzad M, Shabbir A and Naseem N: Oxyresveratrol ameliorates ethanol-induced gastric ulcer via downregulation of IL-6, TNF- $\alpha$, NF-kB, and COX-2 levels, and upregulation of TFF-2 levels. Biomed Pharmacother 110: 554-560, 2019.

44. He H, Feng M, Xu H, Li X, He Y, Qin H, Zhang Y, Tang H and Zou K: Total triterpenoids from the fruits of chaenomeles speciosa exerted gastroprotective activities on indomethacin-induced gastric damage via modulating microRNA-423-5p-mediated TFF/NAG-1 and apoptotic pathways. Food Funct 11: 662-679, 2020.

45. Longman RJ, Douthwaite J, Sylvester PA, Poulsom R, Corfield AP, Thomas MG and Wright NA: Coordinated localisation of mucins and trefoil peptides in the ulcer associated cell lineage and the gastrointestinal mucosa. Gut 47: 792-800, 2000.

46. Katoh M: Trefoil factors and human gastric cancer (review). Int J Mol Med 12: 3-9, 2003

47. Chen J, Zhao KN and Vitetta L: Effects of intestinal microbial(-)elaborated butyrate on oncogenic signaling pathways. Nutrients 11: 1026, 2019.

48. Bultman SJ: Interplay between diet, gut microbiota, epigenetic events, and colorectal cancer. Mol Nutr Food Res 61: 10, 2017.

49. Davie JR: Inhibition of histone deacetylase activity by butyrate. J Nutr 133 (7 Suppl): 2485S-2493S, 2003.

50. Eslami M, Sadrifar S, Karbalaei M, Keikha M, Kobyliak NM and Yousefi B: Importance of the microbiota inhibitory mechanism on the warburg effect in colorectal cancer cells. J Gastrointest Cancer 51: 738-747, 2020

51. Hanson J, Gille A, Zwykiel S, Lukasova M, Clausen BE, Ahmed K, Tunaru S, Wirth A and Offermanns S: Nicotinic acidand monomethyl fumarate-induced flushing involves GPR 109A expressed by keratinocytes and COX-2-dependent prostanoid formation in mice. J Clin Invest 120: 2910-2919, 2010.

52. Benyo Z, Gille A, Kero J, Csiky M, Suchánková MC, Nüsing RM, Moers A, Pfeffer K and Offermanns S: GPR109A (PUMA-G/HM74A) mediates nicotinic acid-induced flushing. J Clin Invest 115: 3634-3640, 2005.

53. Tarnawski AS: Cellular and molecular mechanisms of gastrointestinal ulcer healing. Dig Dis Sci 50 (Suppl 1): S24-S33, 2005.

This work is licensed under a Creative Commons Attribution-NonCommercial-NoDerivatives 4.0 International (CC BY-NC-ND 4.0) License. 